\title{
O TRABALHO E OS TRABALHADORES DA EDUCAÇÃO DE JOVENS E ADULTOS
}

\author{
Gionara Tauchen
}

\section{RESUMO}

Intentamos, através deste artigo, compartilhar o nosso olhar sobre a educação dos jovens e adultos destacando, que nossos construtos não provém apenas um estudo teórico, mas também, prático, proveniente dos projetos de formação continuada de educadores que desenvolvemos. Centraremos nossa análise num ponto, que é, para nós, fundamental: a condição de trabalhador, a qual diz respeito, tanto aos educandos jovens e adultos, quanto aos educadores. Para conduzir este "olhar", formularemos algumas proposições - tomando como referência o ponto de vista da filosofia existencial - que colaboram no desvelamento das relações e contradições que perpassam a cultura, a educação e a divisão social e técnica do trabalho. Encontramos, nesta direção, na vida e obra de Paulo Freire uma posição radicalmente comprometida com a realização de um projeto educacional libertador. Coerente com esta finalidade, buscamos também, as contribuições do filósofo brasileiro Vieira Pinto.

\section{O TRABALHO E A SITUAÇÃO DA EXISTÊNCIA}

As transformações no espaço social e individual são produzidas através do trabalho. No caso específico dos jovens e adultos - tanto educandos quanto educadores - o trabalho os incorpora à etapa vigente da sociedade, ou seja, só subsiste quem realiza trabalho.

O trabalho lança a possibilidade de transformação do próprio homem e das condições materiais de sua existência. Porém aquela não depende, apenas, de um interesse individual. Existe um fundamento social que nos atinge em função da situação de classe, do momento do processo histórico e das forças produtivas nele atuantes. Segundo Vieira Pinto (1985, p. 344), [essa transformação] "não é feita intencionalmente mas decorre da estrutura do sistema, que prefigura a distribuição das oportunidades, com isso reduzindo a uma faixa extremamente estreita a área da opção em que a liberdade individual se mostraria capaz de dar a cada homem, mediante o trabalho que escolhesse, o destino que desejasse".

Em tais condições, o nascimento chega a ser uma "sentença de vida". O papel existencial do trabalho, que seria de fazer-se a si mesmo homem, pode ser impedido de realizar-se. O trabalho imposto ou aceito passivamente por toda a vida parece 
produzir o sujeito. Como bem destaca Vieira Pinto (1985, p. 344), "neste caso, o trabalho inverte o papel a que está destinado. Em vez de ser para o homem, este é que é para o trabalho. O atributo converte-se em substância, o instrumento em origem absoluta. Tal é a essência da escravidão, da servitude, da alienação do trabalho".

Em outras palavras, o leitor já deve ter se deparado com perguntas do tipo "o que você faz", ou feito este questionamento a alguém. Não são raras vezes ouvimos respostas do tipo "professor de Língua Portuguesa" ou "professor de Matemática". A resposta vem acompanhada pela especificidade do que fazemos. Parece que a pessoa é definida pela classificação da sua produção, isto é, a identidade é tragada pela função. Aquilo que produzimos, a nossa função, são passíveis de controle, de racionalização? Caso a resposta seja positiva, faz sentido pensar sobre os riscos de gerenciamento ou administração do nosso ser, ou seja, podemos desaparecer como pessoas em meio às funções que desempenhamos, pois estas podem estar amarradas, controladas, dirigidas.

Ainda sobre a condição de alienação, o trabalho, em certos casos, é realizado distante da experiência expressiva, criadora, na qual o trabalhador tenta compor o seu mundo. Neste caso, o trabalho não é realizado pelo prazer que dele se deriva, mas sim, com o ganho que dele provém. Desse modo, o trabalhador pode se dar ao prazer de fazer as coisas que gosta fora do seu trabalho. Neste contexto, e apenas nele, fazem sentido os reclames daquele professor que conta os dias para aposentadoria, pois esta se apresenta como um ideal de libertação.

Este processo de alienação do trabalho tem, como uma das fontes primeiras, a exclusão dos processos decisórios que dizem respeito ao trabalho social que realizamos. Por este motivo, o educador de jovens e adultos precisa dialogar sobre a percepção da situação social, sobre as causas do "atraso cultural" dos seus educandos. Esta possibilidade não tem outra fonte de ajuda senão através da problematização do próprio trabalho que os sujeitos executam. Tal a razão pela qual toda a reflexão sobre o trabalho recai na discussão do regime social, na divisão social do trabalho.

\section{E O TRABALHO NO ESPAÇO DA DOCÊNCIA?}


O professor que utiliza um livro didático durante a sua aula, por exemplo, vale-se de um instrumento que resume um processo cultural: um bem de consumo em função das finalidades a que se destina e um bem de produção em relação ao processo de produção, fabricação e emprego do material. Este duplo aspecto da cultura nos mostra que uma de suas faces é materializada através de instrumentos e outra, constituída de idéias. As técnicas estão entre estas faces.

\begin{abstract}
Em certos tipos de sociedade, porém, aqueles em que há classes distintas e com oposição de interesses, os dois aspectos não se encontram igualmente distribuídos. Daí resulta a situação em que apenas uma parte, um grupo minoritário, por ser o detentor da cultura enquanto bem de produção, forma a classe daqueles que têm o privilégio de conceber as finalidades sociais, e por isso, aparece como "culto", enquanto o restante, as massas, que somente manejam os bens de produção sem os possuir e só escassamente absorvem os bens de consumo, adquirem a enganosa aparência de parte "inculta" da sociedade (Vieira Pinto, 1979, p. 124).
\end{abstract}

Em decorrência da estruturação da nossa sociedade, o que se passa atualmente é um processo inverso: a cultura parece ser superior ao homem e este, ao invés de ser um bem de produção de si mesmo, torna-se um bem de produção para o outro, convertendo-se, assim, em um instrumento. Aparecem, então, as diferenciações e desigualdades no papel existencial exercido pelos homens no processo produtivo. Nas palavras de Vieira Pinto (1979, p. 127), "a raiz da separação de classes, como conseqüência da posição do indivíduo no processo social da produção dos bens, está na natureza dual da cultura, que, em suas manifestações, materiais e objetivas, é simultaneamente bem de consumo e de produção".

Verifica-se, através da evolução da sociedade - ampliação dos conhecimentos culturais e bens resultantes —, uma diferenciação na apropriação do acervo cultural decorrente do modo de participação de cada indivíduo na produção social. A produção dos bens de consumo ocorre num processo crescente de especialização e divisão concomitante à divisão social do trabalho: "É evidente que o grupo dos que trabalham e quase nada consomem da cultura que produzem, especializando-se no manejo dos instrumentos materiais, das técnicas produtivas, perdem contato com o outro lado da cultura, as idéias, o saber, a ciência, que ficam na cabeça dos privilegiados, enquanto as ferramentas ficam nas mãos dos trabalhadores" (Vieira Pinto, 1979, p. 129). O 
grupo dominante tem o poder de definir a finalidade da idéias, da criação cultural, enquanto a imensa maioria (que alguns chamam de minorias) se vê incumbida de obrar os produtos materiais da cultura.

O resultado desse fato histórico repercute diretamente na criação e produção da ciência e das produções que são consideradas científicas. Um grupo apropria-se do aspecto "subjetivo" da cultura, tomando-se de poderes para definir as finalidades das idéias, fazendo deste ofício a justificação do seu papel histórico. Este processo dá margem para algumas explicações que parecem legitimar uma desigualdade concebida como natural, principalmente no campo educacional.

Um pequeno grupo, que representa os teóricos ou cientistas educacionais, tem como função elaborar as teorias que carregam, inevitavelmente, ideologias e poderes sociais de classe. Algumas destas teorias figuram idéias abstratas construídas através de especulações e práticas educacionais imaginativas. O outro grupo, que tem por espólio o trabalho educativo, parece ser privado da possibilidade de investigar, com fins científicos, a sua prática. Está impedido de voltar-se para a prática numa atitude indagativa, de formar idéias sobre os processos que são materializados diariamente, porque sua obrigação é realizar o trabalho de maneira habitual, ficando na condição de absorvedor das idéias e produtos elaborados pelo outro grupo. Esse não reconhece no grupo minoritário o direito de criar por si mesmo as idéias que considera adequadas para exprimir sua situação social.

Nas palavras de Vieira Pinto (1979, p. 131), "com isso, as classes efetivamente trabalhadoras ficam privadas, não do direito de pensar, que, esse, o exercem constantemente e em natural sentido reivindicatório, mas o direito de ver reconhecidas como expressão da cultura as idéias que elaboram". Esta divisão social do trabalho colabora na difusão do trabalho docente altamente burocratizado. O papel dos professores, nesta lógica, é aplicar instrumentos e recomendações didáticas elaboradas externamente, promovendo o abandono da reflexão crítica sobre os fins educacionais em prol da racionalidade dos meios. Como produto desse deslocamento, os objetivos e fins educacionais são mistificados em função de uma obsessiva eficiência metodológica. 
O trabalho educativo é reduzido ao uso de técnicas associadas ao 'como fazer', deixando de lado o conhecimento dos princípios pedagógicos que perpassam a prática educativa em toda a sua complexidade. Por exemplo, "o que se sugere com isto é que o tipo de relação entre 'meios' e 'fins' que supõe o enfoque positivista do teórico e do prático não serve para entender como, na educação, as finalidades, as políticas e os meios estão intrinsecamente relacionados" (Carr \& Kemmis,1988, p.93).

Esta lógica burocrática tende a reduzir a autonomia dos docentes no que diz respeito ao desenvolvimento, planejamento e avaliação do processo de ensino-aprendizagem. Deste ponto de vista, os professores, encarregados de fazer a prática, são vistos como aplicadores de ações técnicas, instrumentos, não tendo "capacidade" de construir, também, idéias. O saber científico é considerado como $\underline{\mathrm{O}}$ Saber, produto dos homens que se ocupam de fazer 'ciência' ou, como costumamos ouvir no campo educacional, dos intelectuais. Logo, a tendência é menosprezar o saber que não é "científico".

É preciso, portanto, construir formas de rompimento com estes processos culturais desumanos, através de uma reunificação da cultura fundada na perspectiva dialética e histórica, onde o homem produz tanto os objetos quanto as idéias, isto é, age fisicamente, representa mentalmente e sistematiza este processo através do seu trabalho. Nas palavras de Freire (1995, p. 23):

\footnotetext{
Não podemos renunciar à luta pelo exercício de nossa capacidade e nosso direito de decidir e de romper, sem o que não reinventamos o mundo. Neste sentido insisto em que a História é possibilidade e não determinismo. Somos seres condicionados, mas não determinados. É impossível entender a História como tempo de possibilidade se não reconhecermos o ser humano como ser da decisão, da ruptura.
}

Lembremos que, para construir formas de intervenção social, é preciso modificar, entre outras coisas, a compreensão que temos sobre o ato educativo, superando os ranços da educação tradicional que acompanhou nossa formação inicial e seus aspectos, ainda presentes, em nossas práticas. Esta mudança, que implica compromisso, se reveste de uma outra postura frente à prática educativa: ao ensinar, aprendemos e quem aprende também nos ensina. De acordo com Vieira Pinto (1987, p.21), "o caminho que o professor escolheu para aprender foi ensinar. No ato do 
ensino ele se defronta com as verdadeiras dificuldades, obstáculos reais, concretos, que precisa superar. Nessa situação ele aprende".

A união e, às vezes, ruptura, entre o saber popular e o científico é fundamental para qualquer compreensão profunda que se pretenda sobre a realidade, resultando em ações transformadoras desta. Para Freire \& Faundez (1985, p. 60), “a transformação da realidade implica a união desses dois saberes, para alcançar um saber superior que é o verdadeiro saber que pode transformar-se em ação e em transformação da realidade. A separação de ambos é a eliminação de toda possibilidade de compreensão da globalidade e transformação da globalidade".

\section{CONSIDERAÇÕES POSSÍVEIS}

Para a maioria dos professores, teorizar é algo que alguém faz sobre a nossa prática.Ocorre em espaços e tempos distantes da prática cotidiana, no silêncio da noite, na claridade límpida da nossa solidão intelectual. Sem dúvida, estes espaços e tempos são importantes para a prática, mas não podem ser concebidos como a única possibilidade. Esta imagem da teorização, centrada na relação do pensamento sobre a ação, nos parece um tanto individualista, unilateral. Ressalta a força das idéias, da teorização para orientar e dirigir a ação sendo que, do nosso ponto de vista teóricoprático, as circunstâncias da ação também configuram nossas idéias - insights.

Entendemos que a investigação educativa não é apenas uma forma de esclarecimento individual, senão uma forma de ação social coletiva conectada com os ideais de libertação. Por isso, estamos trabalhando, desde 2002, com os professores do Núcleo Estadual de Educação de Jovens e Adultos e Cultura Popular Mário Quintana de Santa Maria. Essa parceria permitiu estabelecer interfaces entre as nossas práticas e investigações, assentando bases para um trabalho colaborativo de fortalecimento da nossa formação continuada.

Utilizamos, como teorias-guia, a educação dialógica freireana e a teoria educacional crítica. Condizente com esta opção, o suporte metodológico da investigação-ação educacional. O foco da investigação localiza-se nas situações educativas e nas autocompreensões que os sujeitos têm sobre elas, buscando a construção de 
um conhecimento mais sistemático e profundo dos problemas particulares, elaborando ações estratégicas compartilhadas para transformá-los.

Nossas construções teóricas iniciais têm se debruçado sobre a explicitação do conceito de Comunidades Epistêmicas. Estamos entendendo a teoria e prática como processos que pertencem a todas as pessoas — processos públicos. Ou seja, consideramos a teoria e a prática em termos de relações sociais e de estruturas sociais. Podemos, inclusive, pensar em redes. Esta analogia pode nos ajudar a aclarar que práticas são submetidas à teorização, quando e a cargo de quem. Quando temos claro que práticas constituem o centro das nossas observações, auto-reflexões, reflexões e construções. Descobrimos, pois, que a teoria e a prática educativa não podem separar-se. A prática cobra uma coerência quando se teoriza sobre ela e a teoria adquire historicidade quando é praticada.

Neste entendimento, as teorias não são palavras mortas nem as práticas, meras condutas mudas. Por serem mutuamente constitutivas, poderemos descobrir os desajustes entre teoria e prática se examinarmos como ambas se relacionam entre si. Nossas práticas levam a efeito as intenções das nossas teorias? Nossas teorias descrevem nossa prática de maneira coerente e compreensiva?

Uma perspectiva crítica sobre teoria e prática requer considerar ambas como problemáticas, bem como, suas relações.

\footnotetext{
Ao menos em potencial, o saber se converte em teoria quando se prova, se justifica e mantém através do debate na esfera pública. A prova e a justificação das novas idéias e formas de ver constituem um processo de teorização que estabelece acordos e desacordos entre o novo saber e o que sabem os outros; mediante sua reconciliação com o que os outros têm trazido ao depósito comum do saber, se faz como um lugar em âmbito público da teoria (Kemmis, 1995, p. 35).
}

Um dos principais objetos do nosso diálogo, que envolve nossas teorias/práticas, tem sido o currículo, os conteúdos curriculares e os materiais didáticos. Temos nos debruçado entorno da deliberação do que deve ser "transmitido" como conteúdo cultural no espaço do Núcleo, pois o conhecimento não é produto de uma seleção neutra. Segundo Freire \& Horton (2003, p.115) "neutralidade é simplesmente seguir a multidão. Neutralidade é apenas ser o que o sistema nos pede que sejamos" (grifo do 
autor). Desse modo, entendemos que o currículo é uma das peças-chave quando falamos de trabalho educativo.

O currículo, como parte de um trabalho educacional libertador, precisa ser produto da deliberação reflexiva dos professores sobre os fundamentos da finalidade educativa que guiará e se realizará através da prática pedagógica. Na perspectiva prática do currículo, os princípios orientam as decisões sobre a seleção dos conteúdos e as experiências de aprendizagem que devem ser realizadas. Estes princípios devem ser criados, aprovados e assumidos pelos professores num processo deliberativo.

Nesta perspectiva curricular, é preciso conhecer como são efetivamente materializados os princípios na prática educativa pois estes, não explicitam as ações concretas que devem ser realizadas. Na prática, a coerência lógica ente a proposta curricular e as ações educativas pode ser desvirtuada. Segundo Angulo Rasco (1990, p. 40), "é imprescindível, portanto, algum tipo de investigação firmemente conectada com a prática, que permita aos participantes, o conhecimento de suas dificuldades e problemas, potencializando o encaminhamento de ações e transformações da realidade educativa".

Segundo o mesmo autor, um currículo sem investigação é uma arbitrariedade, uma aposta na passividade e manipulação dos sujeitos. A investigação, porém, não pode se dar à margem do currículo. O problema mais importante é saber como realizamos as relações entre as idéias / conhecimentos e a realidade vivida, como trabalhamos com os PCNs que traçam conteúdos, objetivos, formas de avaliação, orientações didáticas (metodologias) e as especificidades dos sujeitos e espaços escolares.

A investigação precisa ser realizada, portanto, para os professores e pelos professores. Desse modo, o currículo terá relevância e poderá ser desenvolvido: com a investigação dos professores sobre, na e para a prática educativa. Apple (1994, p. 45), nas suas reflexões sobre o currículo, escreve que "por isso, devemos escrutinar rigorosamente a forma e o conteúdo do currículo, as relações sociais dentro da sala de aula e as maneiras pelas quais conceituamos atualmente esses aspectos, enquanto expressões culturais de determinados grupos em determinadas instituições e em determinadas épocas". 
Neste processo, a reflexão ocorre no encontro dos homens que buscam, em comunhão, compreender os limites e resistências de suas práticas, das condições em que trabalham, da elaboração e re-interpretação dos currículos, do processo de ensino e aprendizagem. A reflexão precisa ser entendida, portanto como um empreendimento colaborativo. Este possibilita a elaboração de novos conhecimentos educacionais no momento em que nos distanciamos do nosso fazer, problematizandoo, compartilhando idéias e interpretações, buscando auxílio em outros achados científicos referentes aos nossos estudos, produzindo uma síntese dialética através do nosso trabalho, da nossa prática docente.

\section{BIBLIOGRAFIA}

ANGULO RASCO, J. F. Investigacion-acción y curriculum: una nueva perspectiva en la investigación educativa. Investigación en la Escuela, n¹1:39-49, Sevilla, 1990.

APPLE, M. W. A política do conhecimento Oficial: faz sentida a idéia de um currículo nacional? In: MOREIRA, A. F. B. e SILVA, T. T. (orgs.). Currículo, Cultura e Sociedade. São Paulo, Cortez 1994.

CARR, W \& KEMMIS, S. Teoría crítica de la enseñanza: la investigación-acción en la formación del profesorado. Barcelona: Martinez Roca, 1988.

FREIRE, P. Research Methods. In: International Institute for Adult Literacy. Paulo Freire: Literacy through Conscientization. Dar-es-Salaan. International Institute for Adult Literacy, 1974.

Pedagogia do oprimido. SP: Paz e Terra, 1981.

. À sombra desta mangueira. $2^{\mathrm{a}}$ ed. São Paulo: Olho d'Água, 1995.

. A importância do ato de ler: em três artigos que se completam. São Paulo: Autores Associados: Cortez, 1983.

FREIRE, P \& FAUNDEZ, A. Por uma pedagogia da pergunta. Rio de Janeiro: Paz e Terra, 1985

KEMMIS, S. La teoría de la práctica educativa (prólogo). In: CARR, W. Una teoría para la educación: Hacia una investigación educativa crítica. España, Madrid: Morata y Fundación Paideia, 1995.

MYLES, H. \& PAULO, F. O caminho se faz caminhando: conversas sobre educação e mudança social. Petrópolis, RJ: Vozes, 2003.

VIEIRA PINTO, A. Sete lições sobre educação de adultos. São Paulo: Autores Associados: Cortez, 1987.

VIEIRA PINTO, A. Ciência e Existência: problemas filosóficos da pesquisa científica. Rio de Janeiro: Paz e Terra, 1979. 